\title{
Numerical Simulations of a Prechamber Autoignition Engine Operating on Natural Gas
}

\author{
S Heyne ${ }^{1}$, G Millot $^{2}$, D Favrat ${ }^{3} *$ \\ ${ }^{1}$ Division of Heat and Power Technology, Department of Energy and Environment, \\ Chalmers University of Technology, SE-412 96 Göteborg, Sweden \\ ${ }^{2}$ ALTRAN SUD-OUEST - Business Unit Flight Physics \& Energetics, \\ BâtimentSynapse, 4 avenue Didier Daurat, FR-31700 Blagnac, France \\ ${ }^{3}$ Industrial Energy Systems Laboratory - Institute of Mechanical Engineering - \\ Ecole Polytechnique Fédérale de Lausanne Station 9, CH-1015 Lausanne, Switzerland \\ E-mail: ${ }^{1}$ stefan.heyne@chalmers.se; ${ }^{2}$ gregory.millot@altran.com; ${ }^{3}$ daniel.favrat@epfl.ch
}

\begin{abstract}
At our laboratory extensive research has been conducted on the conversion of conventional Diesel cogeneration engines to operation on natural gas and biogas. In the framework of this research, a numerical simulation of a prechamber autoignition gas engine has been performed based on an experimental test case. With a simplified finiterate/eddy-dissipation model for the combustion of natural gas, it was possible to properly reproduce the experiment considering the combustion duration, ignition timing and overall energy balance. A modification of the original cylindrical-conical prechamber geometry to a simpler cylindrical one was tested with the simulation model. The influence of burnt gases inside the prechamber was assessed simulating the mixture formation inside the prechamber. The simulations showed little effect of taking into account the non-homogeneities in the gas phase on the combustion duration. The new cylindrical geometry envisaged did not show any improvement in the combustion homogeneity inside the prechamber and its volume (limited by the real engine geometry) is in fact not sufficient to properly ignite the main chamber according to the simulations. The model can be used to further guide design modifications of the prechamber engine to improve performance.
\end{abstract}

\section{Keywords: Cogeneration; prechamber; autoignition; numerical simulation.}

\section{Introduction}

Small scale cogeneration is a common means of decentralized power generation. The installation of such engines in the power size of several hundred $\mathrm{kW}_{\mathrm{e}}$ has increased drastically the last years along with increased energy recovery from wet manure via digestion in agriculture. In January 2009 more than 4000 biogas cogeneration plants were registered in Germany compared to about 200 in 2003 (www.biogaswissen.de). In Switzerland, 1032 plants for small scale cogeneration (below $1 \mathrm{MW}_{\mathrm{e}}$ ) - mainly diesel and gas cogeneration engines - have been in operation in 2007, producing 600 GWh of electricity (Kaufmann \& Gutzwiller, 2008). In order to make best use of the energy content in the fuel, it is of utmost importance to aim at an efficient conversion in the engines. Energy efficiency in general has been identified as one of the key roadmaps towards a sustainable energy future by the International Energy Agency (2008), being a very effective way of decreasing the global greenhouse gas emissions.

At the Industrial Energy Systems Laboratory (LENI) research is investigating the efficient heat and power generation in gas engines equipped with prechamber. A $150 \mathrm{~kW}_{\mathrm{e}}$ Diesel engine has been converted to operation on both natural gas and biogas using unscavanged prechambers triggered by spark-ignition (Roethlisberger \& Favrat, 2002a, 2002b, 2003a, 2003b; Roubaud \& Favrat, 2005). The capability of the engine concept to reduce emissions below the Swiss emission limits for stationary cogeneration engines while keeping high conversion efficiency was demonstrated for both natural gas and biogas. Current work is aiming at further improving the prechamber concept by converting the prechambers from forced ignition with spark plugs to autoignition by compression heating. This would on the one hand reduce maintenance intervals, and on the other hand, a faster combustion is expected yielding higher efficiency and lower emissions. The new engine concept is based on autoignition of the gas mixture inside a heated unscavanged prechamber. Through the temperature control of a limited volume (prechamber) the concept can be considered to be similar as, but easier to control than homogeneous charge compression ignition (HCCI), an engine concept with very low $\mathrm{NO}_{\mathrm{x}}$ emissions. The potential of this new prechamber autoignition concept has been demonstrated by experimental studies on a mono-cylinder test engine operating on natural gas (Heyne, Meier, Imbert \& Favrat, 2009). Untimely auto-ignition lead to a non-optimal combustion behaviour and average efficiencies. Furthermore, high cycle-to-cycle fluctuations have been observed.

To better understand and guide the experimental work, a numerical simulation of the experimental set-up has been performed. For the initial development of the spark-ignition prechambers, fluid dynamics simulations were successfully used to optimize the prechamber shape (Roethlisberger \& Favrat, 2003a). 
Autoignition in an engine being strongly dependent on local conditions, direct coupling between computational fluid dynamics and chemistry was applied in this study, to have a high resolution of the computational domain. Numerical studies with varying levels of detail have been extensively used to study HCCI combustion. Aceves et al. (2001) have validated a multi-zone model on an HCCI engine operating with propane. Heat release rate, $\mathrm{HC}$ and $\mathrm{CO}$ emissions as well as pressure traces were predicted with good agreement. Kong (2007) studied natural gas/DME HCCI combustion using CFD with detailed chemistry. Combustion and operation limits of the engine as well as the influence of the fuel composition were well reproduced by the simulations. Zheng, Zhang \& Zhang (2005) simulated a prechamber autoignition engine with direct injection of natural gas using the GRI3.0 reaction mechanism.

The engine concept studied in this paper is different from their concept in the fact that air and fuel are mixed prior to admission in the engine and no pilot injection into the prechamber is used. Ignition is triggered inside the prechamber by means of a resistive heating of the prechamber walls. As a numerical study using detailed chemistry proved difficulties in convergence and was very intensive in calculation time (Wunsch, Heyne, Vos \& Favrat, 2007), a simplified combustion model implemented in the commercial code Fluent is used in this work. This simpler model aims mainly at guiding the experimental development of the prechamber in order to improve the engine performance. The main goals are to reach a homogeneous ignition inside the prechamber and to have optimum ignition timing for maximum efficiency. The focus with the model presented in this study therefore is on the mixture formation within the prechamber for different geometries and on the determination of the ignition timing. The interaction between experimental and simulation work is schematically represented in Figure 1.

\section{Simulation}

All simulations presented in this paper are based on one experimental test series at conditions given in Table 1, also specifying the basic engine dimensions.

To simplify simulations, the valves are not represented and a closed system is modelled. The geometry is reduced to one quarter of the cylinder given the periodicity imposed by the four nozzle orifices of the prechamber. During the experiment, the inlet valve is closed at $130{ }^{\circ} \mathrm{CA}$ before top dead centre (BTDC) only, but in order to account for the gas motion due to the piston movement, simulations are started at bottom dead centre (BDC). The mesh is made up of hexahedral cells. The piston is a moving surface with its velocity being controlled by a slider-crank shaft law implemented in Fluent.

Table 1. Engine dimensions and simulated experimental conditions.

\begin{tabular}{rc}
\hline \multicolumn{1}{c}{ Parameter } & Value \\
\hline Bore $(\mathrm{mm})$ & 95.25 \\
Stroke $(\mathrm{mm})$ & 114.3 \\
Piston rod length $(\mathrm{mm})$ & 222.25 \\
Compression ratio $\varepsilon$ & 13 \\
$\mathrm{RPM}\left(\mathrm{min}^{-1}\right)$ & 1500 \\
Relative air-to-fuel ratio $\lambda$ & 1.31 \\
Natural gas composition & $\mathrm{CH}_{4} / \mathrm{C}_{2} \mathrm{H}_{6} / \mathrm{C}_{3} \mathrm{H}_{8} / \mathrm{CO}_{2} / \mathrm{N}_{2}$ \\
(mole-\%) & $90.3 / 5.2 / 1.1 / 1.1 / 2.3$ \\
\hline
\end{tabular}

As the piston is moving upwards and downwards, layers of the mesh have to be deleted or added, respectively. This is done within the dead volume using the Layering method. The mesh size decreases from 400000 to 200000 during compression and increases up to 480000 during expansion as illustrated in Figure 2.

The original cylindrical-conical prechamber shape (geometry 1) used during the autoignition experiments was based on former work with spark-ignited prechambers (Roethlisberger \& Favrat, 2002a, 2002b, 2003b). In a previous numerical study on the new autoignition concept it has been shown that the temperature distribution in the original prechamber is too stratified to obtain a homogeneous ignition (Wunsch et al., 2007). Therefore a new simple cylindrical geometry (geometry 2 ) was tested in the simulations, its shape being constrained by the real engine cylinder head geometry. The volume of geometry 2 is $490 \mathrm{~mm}^{3}$ compared to $1630 \mathrm{~mm}^{3}$ for geometry 1 . The two shapes are illustrated in Figure 3. There is no notable difference in the calculation mesh for the two prechamber geometries simulated. For further information on the experimental work performed with the autoignition prechamber, the reader is referred to Heyne et al. (2009).

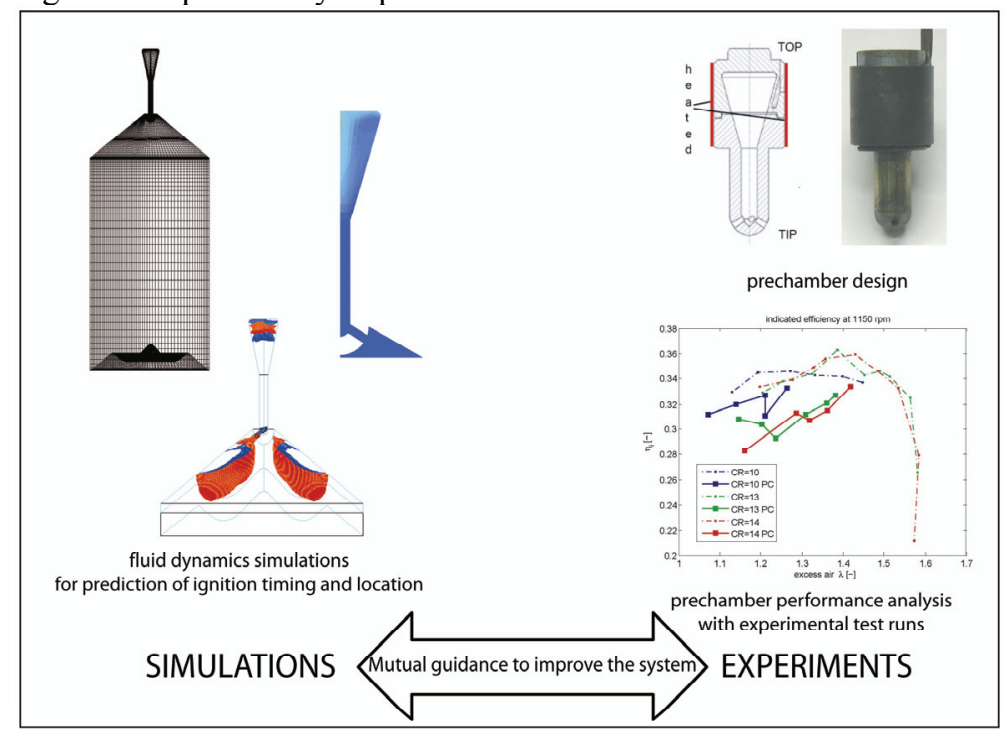

Figure 1: Schematic representation of interaction between experiments and simulations for autoignition prechamber development.(Figure is in color in the on-line version of the paper). 

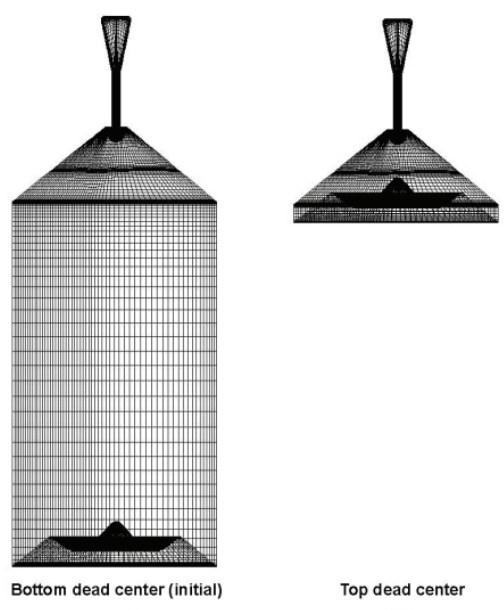

$\theta=-180^{\circ}$

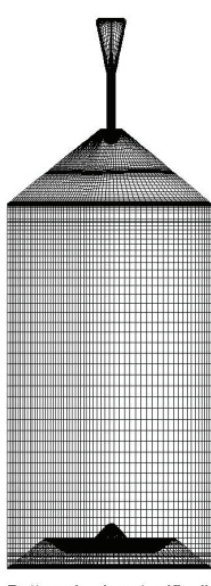

$\theta=180^{\circ}$

Figure 2. Computational mesh for original prechamber geometry.

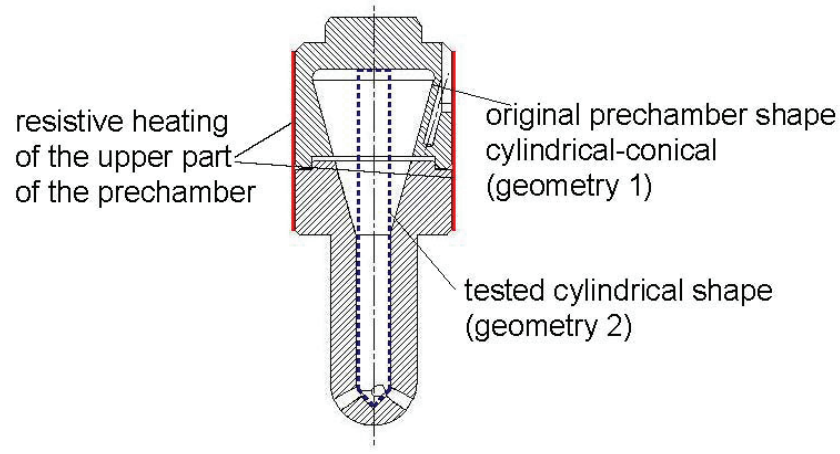

Figure 3. Original prechamber (geometry 1) and cylindrical prechamber (geometry 2) shape.

In order to investigate the mixture formation for both geometries, non-reactive simulations have been run, assuming burnt gases inside the prechamber and a mixture of fresh gases and burnt gases in the main chamber. Subsequent, reactive calculations for both geometries, assuming a homogeneous gas phase, have been run, as well as one simulation taking into account combustion and mixture formation for the original prechamber geometry. In the following, the simulations will be referred to as indicated in Table 2.

Table 2. Simulated cases for the two prechamber geometries.

\begin{tabular}{rcc}
\hline Simulation & $\begin{array}{c}\text { short } \\
\text { name }\end{array}$ & Geometry \\
\hline Non-reactive with burnt gases in prechamber & D1 & 1 \\
Non-reactive with burnt gases in prechamber & D2 & 2 \\
Reactive with homogeneous gas phase & R1 & 1 \\
Reactive with burnt gases in prechamber & R2 & 1 \\
Reactive with homogeneous gas phase & R3 & 2 \\
\hline
\end{tabular}

The chemistry is represented by a global reaction model for natural gas represented by methane, ethane and propane. The combustion reactions are

$\mathrm{CH}_{4}+2 \mathrm{O}_{2} \rightarrow \mathrm{CO}_{2}+2 \mathrm{H}_{2} \mathrm{O}$
$\mathrm{C}_{2} \mathrm{H}_{6}+3.5 \mathrm{O}_{2} \rightarrow 2 \mathrm{CO}_{2}+3 \mathrm{H}_{2} \mathrm{O}$
$\mathrm{C}_{3} \mathrm{H}_{8}+5 \mathrm{O}_{2} \rightarrow 3 \mathrm{CO}_{2}+4 \mathrm{H}_{2} \mathrm{O}$

The composition of the natural gas used during the experiments is known and higher hydrocarbons $(\mathrm{C} 4+)$ have been neglected in the simulation. It has been shown by Turbiez, El Bakali, Pauwels, Rida \& Meunier (2004) that a good representation of natural gas combustion is feasible with this simplification. To model combustion chemistry, the Fluent model finite-rate/eddy-dissipation is used. The reaction rate is both calculated based on a finite-rate Arrhenius model (FR) and an eddy-dissipation model (ED) developed by Magnussen \& Hjertager (1976), the smaller of both values being kept. The mass-based reaction rate of species $i$ is

$R_{i}=\sum_{r} \min \left(R_{i, r}^{F R}, R_{i, r}^{E D}\right)$

where:

$$
\begin{aligned}
& R_{i, r}^{F R}=M_{i}\left(v_{i, r}^{\prime \prime}-v_{i, r}^{\prime}\right) \prod_{j}\left[C_{j, r}\right]^{\left(\eta_{j, r}^{\prime}+\eta_{j, r}^{\prime \prime}\right)} A_{r} T^{\beta} e^{-\frac{E_{a, r}}{R T}} \\
& R_{i, r}^{E D}=v_{i, r}^{\prime} M_{i} A \rho \frac{\varepsilon}{k} \min \left(\min _{R}\left(\frac{Y_{R}}{v_{R, r}^{\prime} M_{R}}\right), B \frac{\sum_{P} Y_{P}}{\sum_{j}^{N} v_{j, r}^{\prime \prime} M_{j}}\right)
\end{aligned}
$$

with $M_{i}$ the molar mass of species $i, v_{i, r}^{\prime}$ and $v_{i, r}^{\prime \prime}$ the stoichiometric coefficient for the reactant respectively product $i$ for reaction $r, C_{j, r}$ the molar concentration of species $j$ in reaction $r, \eta_{j, r}^{\prime}$ and $\eta_{j, r}^{\prime \prime}$ the rate exponents for reaction respectively product species $j$ in reaction $r, A_{r}$ the pre-exponential factor for reaction $r, \beta$ the temperature exponent, $E_{a}$ the activation energy and $R$ the universal gas constant. For the eddy dissipation model, $A$ and $B$ denote empiric constants, $Y_{P}$ the mass fraction of any product species $P, Y_{R}$ that of a particular reactant $R . \varepsilon$ represents the turbulent dissipation rate and $k$ the kinetic energy. Due to the relatively low temperature before ignition, it is the Arrhenius law (FR) that controls chemistry and determines the autoignition timing whereas the eddy-dissipation model (ED) controls the flame speed during combustion as high temperatures result in very high reaction rates calculated based on the Arrhenius model.

The values for the rate constants used in the Arrhenius model were taken from the built-in database of Fluent and left unmodified. The empirical constant $A$ of the eddydissipation model is generally set to a numeric value of 4 , and $B$ to 0.5 (Magnussen \& Hjertager, 1976). Based on the combustion duration of the experiment the value of $A$ was adjusted and increased by a factor of 10 . This adaptation is consistent with other work where the value of both $A$ and $B$ have been increased by a factor of 8 for simulating turbulent premixed flames (Magnussen \& Hjertager, 1976). The $k \varepsilon$-realizable model and standard wall functions are used to model turbulence. Thermal effects in the diffusion equation are neglected.

The boundary conditions to be specified are the wall temperature for both prechamber and main chamber. The prechamber wall temperature is measured by a thermocouple during the experiments. For the main chamber, based on a heat balance taking into account the cooling circuit, the mean temperature of the cylinder gases and the heat transfer coefficients, a mean wall temperature can be established. The latter had been evaluated during a former work (Wunsch et al., 2007). Initial conditions include mixture composition, pressure, temperature and level of turbulence. Two different cases simulated have to 
be considered here. Simulations with homogeneous composition all over the gas phase (simulations R1 and R3) simply use the mixture composition calculated based on the relative air-to-fuel ratio $\lambda=1.31$ from the experiments and the burnt gases left in the dead volume. When taking into account the mixture formation inside the prechamber (simulations D1, D2 and R2), it is assumed that the gases inside the prechamber are initially composed of burnt gases only. For the main chamber the same mixing rule as for the homogeneous cases applies. The initial pressure for the simulations could not be based on the measured value as the signal is very noisy at BDC due to the valve motion and the induced pressure fluctuations. In addition, it has to be accounted for the fact that during the experiment the valves are only closing at $130^{\circ} \mathrm{CA}$ BTDC while the simulation starts at BDC as a closed system. Therefore, this value is calculated for an adiabatic compression in order to obtain the experimental value of maximum pressure for a motored cycle without combustion, assuming that the pressure at BDC is not very dependent on the intake gas composition. Once composition, pressure and trapped mass are known, the temperature is obtained by the ideal gas law. For simulations D1, D2 and R2, the temperature of the gases inside the prechamber is assumed to be equal to the experimentally measured exhaust gas temperature. The level of initial turbulence is based on literature and preliminary simulations. A summary of the boundary and initial conditions for the different simulations is given in Table 3.

Table 3. Boundary and initial conditions for the simulations (in parenthesis: prechamber gas phase composition and temperature for simulations D1, D2, and R2). Based on the experimental test case (engine speed $1500 \mathrm{~min}^{-1}$, relative air-to-fuel ratio $\lambda=1.31$, compression ratio $C R=13$ ).

\begin{tabular}{|c|c|}
\hline \multicolumn{2}{|l|}{ Boundary conditions } \\
\hline Main chamber wall and piston temperature $(\mathrm{K})$ & 376 \\
\hline Prechamber wall temperature $(\mathrm{K})$ & 793.2 \\
\hline \multicolumn{2}{|l|}{ Initial conditions } \\
\hline $\mathrm{CH}_{4}$ (wt- $\%$ mass) & $3.537(0)$ \\
\hline $\mathrm{C}_{2} \mathrm{H}_{6}$ (wt- $\%$ mass $)$ & $0.320(0)$ \\
\hline $\mathrm{C}_{3} \mathrm{H}_{8}$ (wt- $\%$ mass $)$ & $0.100(0)$ \\
\hline $\mathrm{CO}_{2}$ (wt- $\%$ mass $)$ & $1.018(11.96)$ \\
\hline $\mathrm{H}_{2} \mathrm{O}$ (wt- $\%$ mass) & $0.725(9.41)$ \\
\hline $\mathrm{O}_{2}$ (wt- $\%$ mass $)$ & $20.93(5.626)$ \\
\hline $\mathrm{N}_{2}$ (wt- $\%$ mass) & $73.37(73.37)$ \\
\hline Pressure (bar) & 0.86 \\
\hline Temperature $(\mathrm{K})$ & $353.4(718)$ \\
\hline Turbulent kinetic energy $\kappa\left(\mathrm{m}^{2} / \mathrm{s}^{2}\right)$ & 5 \\
\hline Turbulent dissipation rate $\varepsilon\left(\mathrm{m}^{2} / \mathrm{m}^{3}\right)$ & 1000 \\
\hline
\end{tabular}

\section{Results}

The investigation of mixture formation for the two geometries showed that the original prechamber shape results in a very homogeneous distribution considering the relative air-to-fuel ratio $\lambda$. Figure 4 shows the range of $\lambda$ at $27^{\circ} \mathrm{CA}$ BTDC in a cut plane of the prechamber and illustrates well that the maximal value of $\lambda$ for geometry 1 is about 1.6 in the top centre region of the prechamber. For geometry 2 little mixing of the burnt gases and the fresh gases occurs and the burnt gases are actually only compressed at the top of the prechamber. The $\lambda$ value exceeds 2 in the top of the prechamber. The relative air-tofuel ratio being an important parameter for ignition timing, the original geometry seems more favourable for homogeneous ignition.

The main reason for the bad mixing for geometry 2 is the fact that the swirl motion - induced by the holes connecting prechamber and main chamber which are inclined by $10^{\circ}$ in the radial direction - dies out due to the constant small prechamber diameter. For the original prechamber shape it is mainly this swirl that renders the mixture more homogeneous. In addition, a stronger effect of recirculation for geometry 1 enhances the mixing.

The reactive calculations all showed good agreement with the experimental ignition timing and combustion duration. Table 4 illustrates that the moment of $5 \%$ heat release $\theta_{5 \%}$ coincides acceptably well with the experimental data for the two simulations R1 and R2. Simulation R2, taking into account the mixture formation in the prechamber shows a particularly good agreement. The same applies for the combustion duration. Simulation R3 results in an earlier ignition and a longer combustion duration.

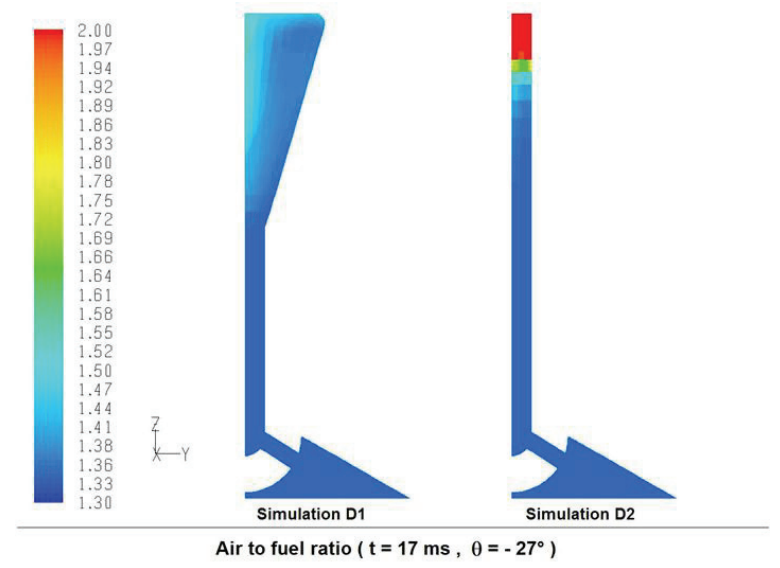

Figure 4. Lambda distribution for both prechamber geometries at $27^{\circ} \mathrm{CA}$ BTDC. Simulations D1 and D2. (Figure is in color in the on-line version of the paper).

The parameter $\Delta_{\text {ignition }}$ in Table 4 represents the delay between the complete ignition of the prechamber, indicated by a small pressure peak, and the moment of $5 \%$ heat release in the main chamber. It can be interpreted as a measure of the capability of the prechamber to ignite the main chamber. It can be seen that for geometry 2 , the value is more than 3 times higher compared to geometry 1 . This indicates that the volume of geometry 2 is not sufficient to rapidly ignite the main chamber which is also documented by the distinctively lower peak pressure of the simulation run R3 compared to the other simulations.

The fact that the volume of the new prechamber geometry is not sufficient to rapidly ignite the main chamber can also be observed in Figure 5, illustrating the flame front at $5 \%$ heat release for each simulation. For simulation R3 it shows that the jets issuing from the prechamber are not penetrating deep enough into the main chamber to properly ignite the mixture. The combustion in the main chamber in consequence is rather controlled by the heating due to compression than by the prechamber jets. Comparing simulations R1 and R2 it can be observed that for the homogenous gas phase simulation $\mathrm{R} 1$, the jets are penetrating deeper into the main chamber. This results in consequence in slightly shorter combustion duration. 
Table 4. Performance indicators for the experiment and the different reactive simulations.

\begin{tabular}{|c|c|c|c|c|}
\hline & Experiment & $\begin{array}{c}\text { Simulation R1 } \\
\text { (Geometry 1) }\end{array}$ & $\begin{array}{c}\text { Simulation R2 } \\
\text { (Geometry 1) }\end{array}$ & $\begin{array}{c}\text { Simulation R3 } \\
\text { (Geometry 2) }\end{array}$ \\
\hline Cumulative $5 \%$ heat release $\Theta_{5 \%}\left({ }^{\circ} \mathrm{CA}\right)$ & -18 & -20.7 & -17.5 & -14.2 \\
\hline Cumulative $90 \%$ heat release $\Theta_{90 \%}\left({ }^{\circ} \mathrm{CA}\right)$ & -2 & -2.9 & 0.6 & 9.3 \\
\hline Combustion duration $\Delta_{\text {combustion }}\left({ }^{\circ} \mathrm{CA}\right)$ & 16 & 17.8 & 18.7 & 23.5 \\
\hline Prechamber ignition delay $\Delta_{\text {ignition }}\left({ }^{\circ} \mathrm{CA}\right)$ & - & 4.3 & 5.1 & 16.3 \\
\hline Break specific fuel consumption $(\mathrm{g} / \mathrm{kWh})$ & 472.5 & 370.8 & 359.8 & 377.0 \\
\hline Peak cycle pressure (bar) & 69.81 & 80.97 & 78.97 & 69.15 \\
\hline
\end{tabular}

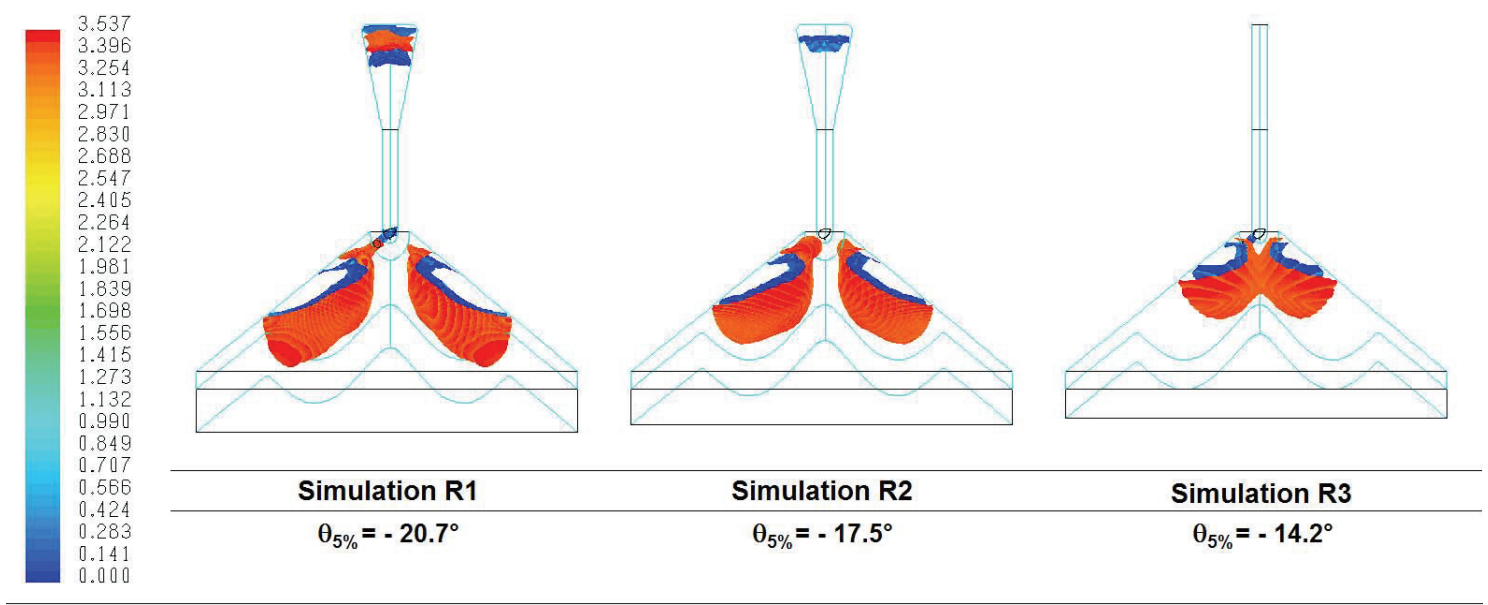

Mass fraction of methane (\%)

Figure 5. Flame front at 5\% heat release for simulations $\mathrm{R} 1, \mathrm{R} 2$ and $\mathrm{R} 3$. Iso-surfaces for $95 \%$ of initial $\mathrm{CH}_{4}$ concentration (red) and $10 \%$ of initial $\mathrm{CH}_{4}$ concentration (blue). (Figure is in color in the on-line version of the paper).

Due to the higher fuel concentration inside the prechamber, the energy release is higher and the velocity of the gases leaving the prechamber is more elevated compared to simulation R2. The differences in the overall combustion duration $\Delta_{\text {combustion }}$ are negligible between the two simulations. It has to be mentioned that for all simulations - as for the experiment - the ignition timing is very early. This leads to quite high break specific fuel consumption figures in both experiments and simulation. As in the simulation the combustion is complete, whereas the unburned hydrocarbon level is quite high for the experiments, the figures are better for the simulation. This undesired early ignition timing could be influenced by reducing the prechamber wall temperature in order to shift ignition closer to TDC or modifying the prechamber shape.

A comparison of the pressure traces for simulations R1 and R2 with the measured pressure trace illustrated in Figure 6 shows that the peak pressure is over predicted by both simulations. Simulation R2 results in a lower peak pressure indicating the necessity of taking into account the mixture inhomogeneities for the simulations.

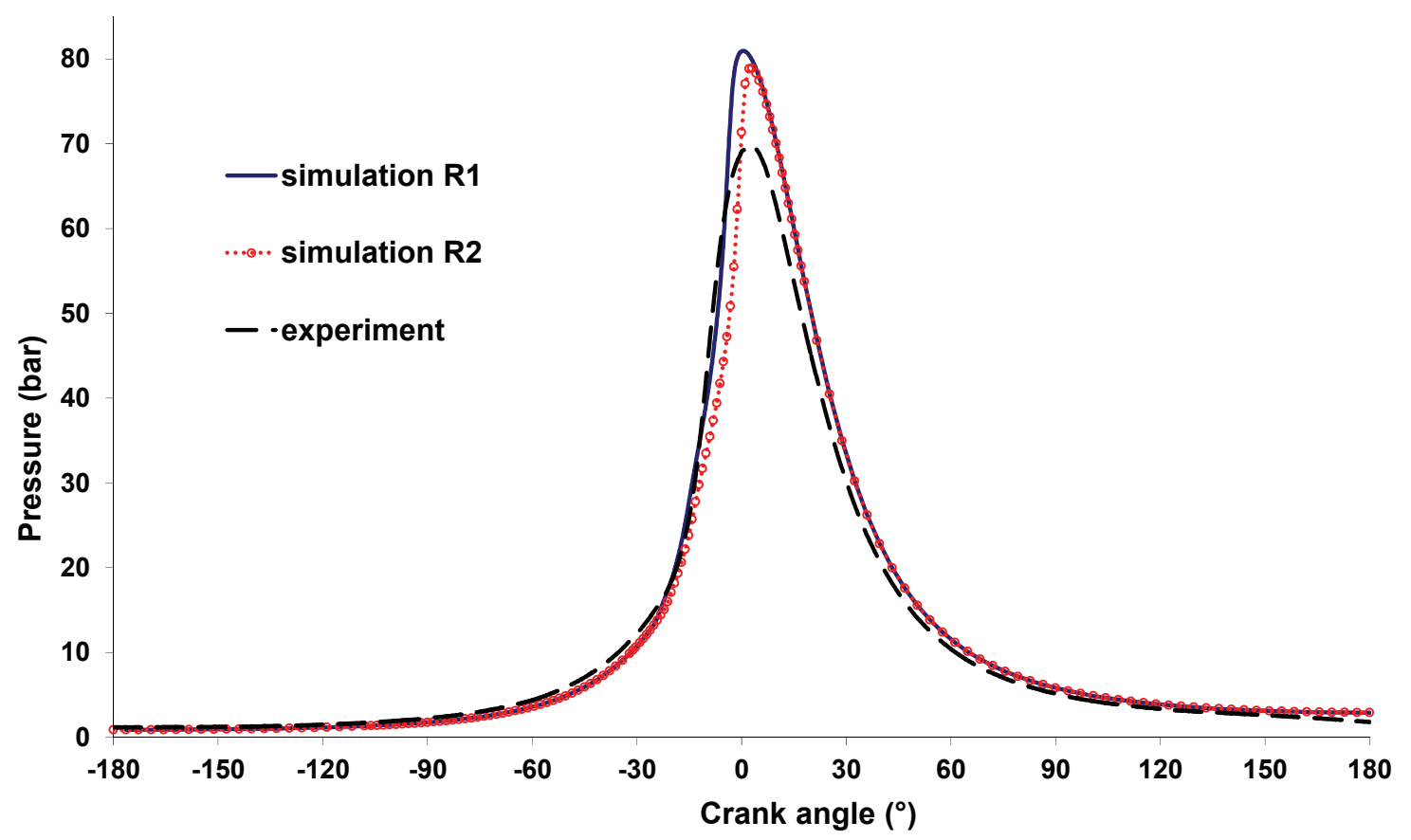

Figure 6. Pressure curve for simulations $R 1$ and R2 in comparison to the experimental pressure curve (engine speed 1500 min $^{-1}$, relative air-to-fuel ratio $\lambda=1.31$, compression ratio $C R=13$ as specified in Table 1). (Figure is in color in the online version of the paper). 
The over prediction of the pressure in the simulations can be related to several aspects in the model: no crevice flow has been taken into account in the simulation model. A rough estimation of losses through the crevice between piston and cylinder liner is about $1 \%$ of the charge, leading to a decrease in maximum pressure in the experiment compared to the simulation. These losses could be taken into account in the future using an implemented 0-D crevice flow model in Fluent. Another important aspect leading to differences between experimental and simulated pressure trace is the fact that during experiments, there is a large fraction of unburned hydrocarbons in the exhaust (about $6 \%$ of the charge, see also Table 5) whereas the combustion is complete according to the simplified combustion model used in the simulation. This leads in turn to an overestimation of the temperature respectively pressure during combustion for the model. Finally, the simplified combustion model does not account for the numerous reactions going on prior to ignition where intermediate species are formed in partially endothermic reactions. These reactions also have a dampening effect on the temperature/pressure increase in the experiment that is not taken into account in the simulation.

A comparison of the experimental case and simulation $\mathrm{R} 2$ considering the energy balance is illustrated in Table 5 .

Table 5. Overall energy balance. Experimental and simulated values. Orders of magnitude indicated in literature (Heywood, 1988).

\begin{tabular}{rccccc}
\hline & $\dot{\boldsymbol{E}}_{\text {total }}$ & $\boldsymbol{P}_{\text {brake }}$ & $\dot{\boldsymbol{Q}}_{\text {total }}$ & $\dot{\boldsymbol{E}}_{\text {exhaust }}$ & $\dot{\boldsymbol{E}}_{\text {unburnt }}$ \\
\hline Experiment (W) & 17890 & 5814 & 6368 & 4586 & 1122 \\
\% of $\dot{E}_{\text {total }}$ & 100 & 32.5 & 35.6 & 25.6 & 6.3 \\
Simulation R2 (W) & 17890 & 7636 & \multicolumn{2}{c}{10254} & 0 \\
\% of $\dot{E}_{\text {total }}$ & 100 & 42.7 & \multicolumn{2}{c}{53.3} & 0 \\
Literature value (\%) & 100 & $25-38$ & $18-41$ & $22-45$ & $1-5$ \\
\hline
\end{tabular}

As only the compression and combustion phase are modelled, it is not possible to detail the heat flux $\dot{Q}_{\text {total }}$ and the energy flux leaving with the exhaust gases $\dot{E}_{\text {exhaust }}$ for the simulation. The sum of both results from the calculation of the overall energy balance. It can be seen that for both the experiment and simulation, the orders of magnitude given in literature (Heywood, 1988) are attained. This holds except for the high value of unburned hydrocarbons measured in the experiments.

Based on the simulations, an instantaneous energy balance was established as shown in Figure 7. Small deviations are noted (peaks in the imbalance curve) during the combustion process that can be attributed to numerical instabilities. The time step has been controlled manually and reduced down to $0.01 \mathrm{~ms}$ (corresponding to $0.09^{\circ} \mathrm{CA}$ at $\mathrm{RPM}=1500 \mathrm{~min}^{-1}$ ) around TDC in order to ensure the validity of the results. A further reduction would be desirable during the combustion phase but even with the current setup the simulations were very time consuming (more than 10 days for e.g. simulation R2 on two parallel calculation nodes). The energy balances - both overall and instantaneous - could be used to further validate the model based on experimental measurements.

\section{Conclusions}

A numerical model for the simulation of a compression and combustion cycle for a prechamber autoignition engine has been developed. With a finite-rate/eddy-dissipation model it was possible to well represent an experimental test case. Scaling of the empiric constant A of the eddydissipation model by a factor of 10 was however necessary. Further experimental data should be used to validate this number. Two different prechamber geometries have been tested to assess their respective combustion performance. The small cylindrical prechamber has shown to be too small to properly ignite the main chamber.

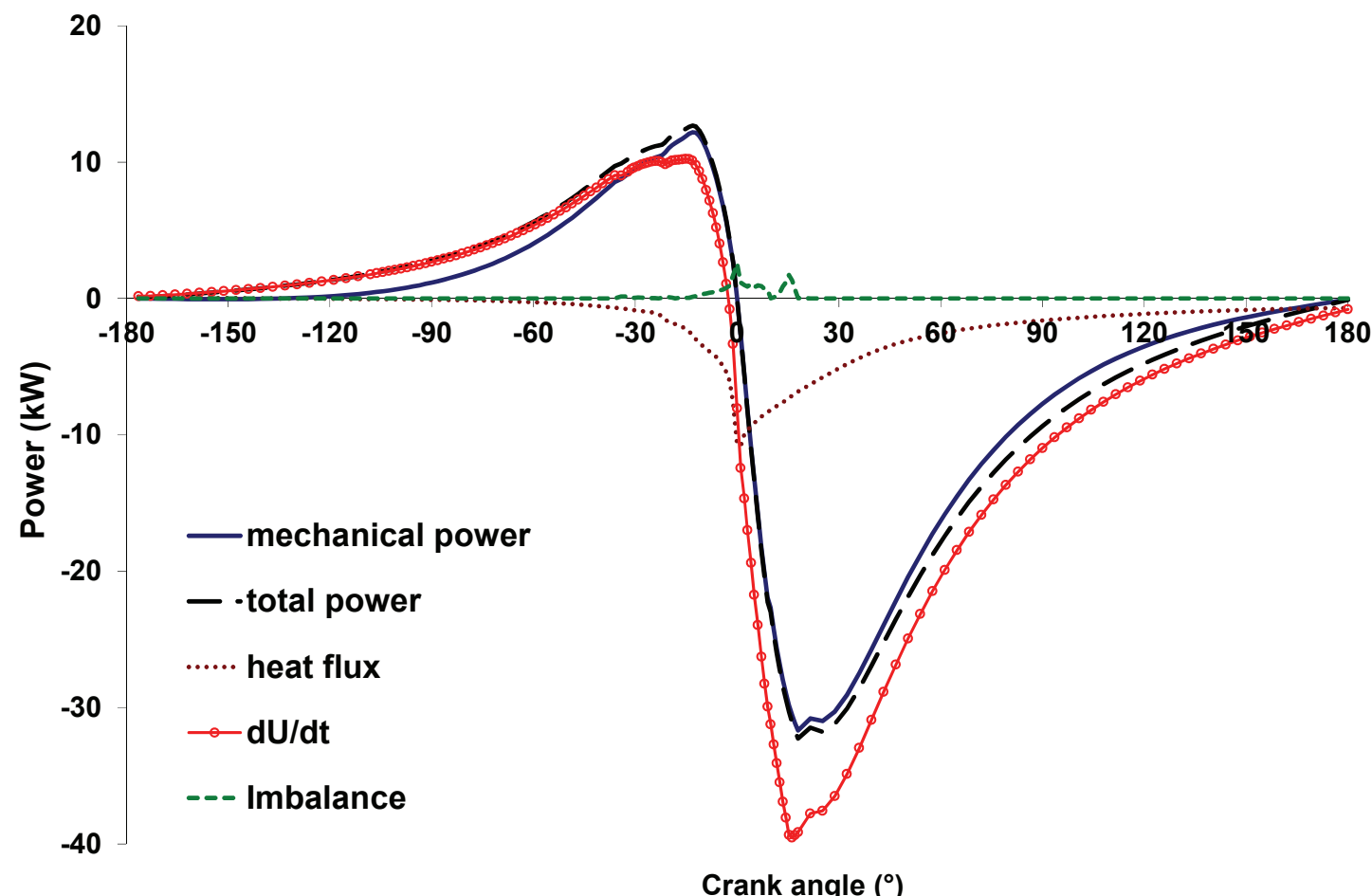

Figure 7. Instantaneous energy balance for simulation 22 (engine speed 1500 min-1, relative air-to-fuel ratio $\lambda=1.31$, compression ratio $C R=13$ as specified in Tab. 1). (Figure is in color in the on-line version of the paper). 
The mixture formation in the cylindrical-conical prechamber geometry is more favourable for a homogeneous ignition. The ignition timing was well represented in the simulations and the combustion duration reproduced with acceptable accuracy. An overall energy balance of the simulation is in good agreement with the experimental case to the extent it can be expected. The combustion was complete for the simulations, thus underestimating the unburned hydrocarbon emissions and thereby predicting too high cycle peak pressures. The numerical model can be used to guide future design modifications of the prechamber engine. Different prechamber geometry designs might be tested for combustion homogeneity and ignition timing. Further work might be carried out on validating the scaled model with further experimental data. A full engine cycle simulation would be necessary to completely compare the energy balances, making it necessary to include the intake and exhaust valves, considerably increasing the modelling effort and calculation times. The existing model could though be used to investigate the influence of cycle-by-cycle fluctuations on the ignition timing that were observed during the experiments by evaluating the influence of changes in the air-to-fuel ratio and in the charge on the ignition timing.

\section{Acknowledgements:}

This project has been financially supported by the Swiss National Science Foundation (subsidy number 200020105487).

\section{Nomenclature}

\begin{tabular}{ll} 
& \multicolumn{1}{c}{ Abbreviations } \\
CA & crank angle \\
CFD & computational fluid dynamics \\
DME & dimethyl ether \\
BDC & bottom dead centre \\
BTDC & before top dead centre \\
FR & finite rate Arrhenius model \\
ED & eddy-dissipation model \\
HC & hydrocarbons \\
NOx & nitric oxides \\
CO & carbon monoxide \\
HCCI & homogeneous charge compression ignition \\
CR & compression ratio \\
& \\
$A$ & empiric constant (ED) \\
$A_{r}$ & pre-exponential factor for reaction $r(\mathrm{FR})$ \\
$B$ & empiric constant (ED) \\
$C_{i, r}$ & molar concentration of species $j$ in reaction $r$ \\
$E_{a}$ & activation energy \\
$\dot{E}_{\text {exhaust }}$ & energy of exhaust gases \\
$\dot{E}_{\text {total }}$ & total energy flux \\
$\dot{E}_{\text {unburnt }}$ & energy loss due to unburned fuel \\
$M_{i}$ & molar mass of species $i$ \\
$P_{\text {brake }}$ & brake power \\
$\dot{Q}_{\text {total }}$ & total heat flux from combustion chamber \\
$R_{i}$ & reaction rate for species $i$ \\
$T$ & temperature \\
$Y_{p}$ & mass fraction of any product species $(\mathrm{ED})$ \\
$Y_{R}$ & mass fraction of particular reactant species $(\mathrm{ED})$ \\
&
\end{tabular}

\begin{tabular}{ll}
$\beta_{r}$ & \multicolumn{1}{c}{ Greek symbols } \\
$\Delta_{\text {combustion }}$ & $\begin{array}{l}\text { temperature exponent for reaction } r(\mathrm{FR}) \\
\text { overall combustion duration } \\
\Delta_{\text {ignition }}\end{array}$ \\
$\varepsilon$ & $\begin{array}{l}\text { and } \Theta_{5 \%} \\
\text { turbulent dissipation rate }\end{array}$ \\
$v^{\prime}$ & stoichiometric coefficient for reactant (FR) \\
$v^{\prime \prime}$ & stoichiometric coefficient for product (FR) \\
$\kappa$ & kinetic energy \\
$\lambda$ & relative air-to-fuel ratio \\
$\eta^{\prime}$ & rate exponent for reactant species (FR) \\
$\eta^{\prime \prime}$ & rate exponent for product species (FR) \\
$\Theta$ & cumulative heat release during combustion
\end{tabular}

\section{References:}

Aceves, S., Flowers, D., Martinez-Frias, J., Smith, J. R., Westbrook, C. K., Pitz, W., Dibble, R., et al. (2001). A sequential fluid-mechanic chemical-kinetic model of propane HCCI combustion: SAE Technical Paper Series No. 2001-011027. Society of Automotive Engineers.

Heyne, S., Meier, M., Imbert, B. \& Favrat, D. (2009). Experimental investigation of prechamber autoignition in a natural gas engine for cogeneration. Fuel, 88(3), 547-552.

Heywood, J.B. (1988), Internal Combustion Engine Fundamentals, New York, NY: McGraw-Hill.

International Energy Agency. (2008). Energy Technology Perspectives 2008 - Scenarios and Strategies to 2050. Paris, France: OECD/IEA.

Kong, S.-C. (2007). A study of natural gas/DME combustion in HCCI engines using CFD with detailed chemical kinetics. Fuel, 86(10-11), 1483-1489.

Magnussen, B. \& Hjertager, H. (1976). On mathematical modeling of turbulent combustion with special emphasis on soot formation and combustion. Proceeding of 16th Symposium (International) on Combustion, 719-729.

Roethlisberger, R.P. \& Favrat, D. (2002a). Comparison between direct and indirect (prechamber) spark ignition in the case of a cogeneration natural gas engine, Part I: Engine geometrical parameters. Applied Thermal Engineering, 22(11), 1217-1229.

Roethlisberger, R.P. \& Favrat, D. (2002b). Comparison between direct and indirect (prechamber) spark ignition in the case of a cogeneration natural gas engine, Part II: Engine operating parameters and turbocharger characteristics. Applied Thermal Engineering, 22(11), 1231-1243.

Roethlisberger, R.P. \& Favrat, D. (2003a). Investigation of the prechamber geometrical configuration of a natural gas spark ignition engine for cogeneration: Part I. Numerical simulation. International Journal of Thermal Sciences, 42(3), 223-237.

Roethlisberger, R.P. \& Favrat, D. (2003b). Investigation of the prechamber geometrical configuration of a natural gas spark ignition engine for cogeneration: Part II. Experimentation. International Journal of Thermal Sciences, 42(3), 239-253.

Roubaud, A. \& Favrat, D. (2005). Improving performances of a lean burn cogeneration biogas engine equipped with combustion prechambers, Fuel, 84(16), 2001-2007. 
Kaufmann, U. \& Gutzwiller, S. (2008). Thermische Stromproduktion inklusive Wärmekraftkopplung (WKK) in der Schweiz: Summary Report 2007. Swiss Federal Office of Energy.

Turbiez, A., El Bakali, A., Pauwels, J. F., Rida, A. \& Meunier, P. (2004), Experimental study of a low pressure stoichiometric premixed methane, methane/ethane, methane/ethane/propane and synthetic natural gas flames. Fuel, 83(7-8), 933-941.
Wunsch, D., Heyne, S., Vos, J.B. \& Favrat, D. (2007). Numerical Flow Simulation of a Natural Gas Engine Equipped with an Unscavanged Auto-Ignition Prechamber. European Combustion Meeting, Chania/Greece, Combustion Institute.

Zheng, Q.P., Zhang, H.M. \& Zhang, D.F. (2005). A computational study of combustion in compression ignition natural gas engine with separated chamber. Fuel, 84(12-13), $1515-1523$. 